\title{
DOCÊNCIA UNIVERSITÁRIA NUM PARADIGMA DA COMPLEXIDADE: possibilidades de formação continuada no stricto sensu
}

\author{
University teaching in a paradigm of \\ complexity: opportunities for Master's \\ degrees continuing education
}

\author{
Marilda Aparecida Behrens \\ Professora do Mestrado e Doutorado em Educação e do Curso de Pedagogia da \\ Pontifícia Universidade Católica do Paraná (PUCPR), Curitiba, PR - Brasil: e-mail: \\ marilda.aparecida@pucpr.br
}

\section{Resumo}

Este artigo relata um dos processos de intervenção do Grupo Paradigma Educacionais e Formação de Professores (PEFOP) que, por meio de pesquisa-ação, focaliza uma proposta de formação pedagógica continuada dos professores, que frequentaram a disciplina de "Paradigmas Educacionais na Prática Pedagógica", no Mestrado e

Rev. Diálogo Educ., Curitiba, v. 10, n. 29, p. 27-44, jan./abr. 2010 
Doutorado, no stricto sensu do Programa de Pós-Graduação em Educação (PPGE), da Pontifícia Universidade Católica do Paraná (PUCPR). O grupo PEFOP atua na Linha de Pesquisa "Teoria e prática pedagógica na formação de professores". Neste relato, busca-se descrever a experiência vivenciada num processo de formação pedagógica e compartilhar as possibilidades apresentadas pelos docentes a partir do envolvimento nesta caminhada. A investigação sobre a formação pedagógica dos professores universitários acompanha esta pesquisadora por mais de trinta anos, especificamente nos últimos quatorze, por meio da atuação na consolidação do grupo PEFOP. Atualmente, compõem o grupo quatro professores doutores que atuam no PPGE, oito mestrandos, três doutorandos, quatro professores da Graduação, dois alunos PIBIC e dois alunos da Graduação. O grupo tem focado problemáticas sobre os paradigmas inovadores na docência universitária, em especial, o paradigma da complexidade. Incluem também investigações sobre os processos pedagógicos e suas tendências, profissionalização no trabalho docente, formação profissional do professor pesquisador, as metodologias que busquem a produção do conhecimento, entre outros temas. Considerando essas temáticas significativas e relevantes, o grupo tomou como objeto de estudo a "Prática Pedagógica dos Professores Universitários" e desenvolveu esta pesquisa-ação que buscou propor um processo de intervenção com a finalidade de investigar as contribuições dos professores e pesquisadores para a qualificação da docência na Educação Superior, durante a formação continuada no stricto sensu.

Palavras-chave: Prática Pedagógica. Docência na universidade. Paradigma da complexidade. Formação pedagógica continuada.

\begin{abstract}
This article reports an intervention processes of the PEFOP (Paradigm Education and Teacher Education), through action research, focusing on a proposal for continuing educational training of teachers, who attended the course "educational paradigms in educational", at the master's and doctorate in restric
\end{abstract}

Rev. Diálogo Educ., Curitiba, v. 10, n. 29, p. 27-44, jan./abr. 2010 
sense of the Post-Graduate Education (NGP), at Pontifícia Universidade Católica do Paraná (PUCPR). The group operates in PEFOP Line Research Theory and pedagogical practices in teacher education. In this report, we seek to describe an experience in a process of teacher training and share the possibilities presented by teachers from involvement in this walk. Research on teacher training college attached to this researcher for over thirty years, and specifically in the past fourteen years, through action in the consolidation group PEFOP. Currently make up the group four teachers who work in doctors PPGE, eight Master's students, three doctoral students, four teachers graduation, PIBIC two students and two graduate students. The group has focused on the problematic paradigm innovators in university teaching, in particular, the paradigm of complexity. They also include research into the pedagogical processes and trends, professionalism in teaching, training of teacher researcher, the methodologies that seek the production of knowledge, among other topics. Considering these issues meaningful and relevant, the group took as its object of study "Pedagogical Practice of University Teachers" and developed this action research that aimed to propose an intervention process in order to investigate the contributions of teachers and researchers for the classification of teaching in higher education, during continuing education course.

Keywords: Pedagogical Practice. Teaching at the university. Complexity paradigm. Teacher training.

\section{INTRODUÇÃO}

A formação pedagógica dos professores universitários tem acompanhado a trajetória de quatorze anos do grupo de pesquisa: "Paradigma Educacionais e Formação de Professores- PEFOP", dentro da Linha de Pesquisa "Teoria e prática pedagógica na formação de professores", no Programa de Pós-Graduação em Educação (PPGE) da Pontifícia Universidade Católica do Paraná (PUCPR). O grupo PEFOP investiga a formação pedagógica dos professores universitários

Rev. Diálogo Educ., Curitiba, v. 10, n. 29, p. 27-44, jan./abr. 2010 
e atualmente está constituído por quatro professores doutores que atuam no PPGE, oito mestrandos, três doutorandos, quatro professores da graduação, dois alunos PIBIC e dois alunos da graduação.

O grupo de pesquisa PEFOP tem pesquisado temáticas sobre a formação pedagógica na docência e tem focado problemáticas sobre a ação docente que envolve os paradigmas conservadores e inovadores, em especial, o paradigma da complexidade. Dentro desta abordagem complexa, investiga os processos pedagógicos e suas tendências, a profissionalização no trabalho docente, a formação profissional do professor pesquisador, as metodologias que buscam a produção do conhecimento, entre outros temas. Considerando esses referenciais significativos e relevantes, o grupo desenvolveu um projeto de pesquisa baseado num processo de intervenção com um grupo de docentes universitários, durante a formação continuada no stricto sensu. A pesquisa focalizou as contribuições para a qualificação da docência na Educação Superior, tomando como objeto de estudo a "Prática Pedagógica dos Professores Universitários".

Este artigo relata o processo de pesquisa-ação focalizada numa proposta de formação pedagógica continuada dos professores que frequentaram a disciplina de "Paradigmas Educacionais na Prática Pedagógica", no stricto sensu do PPGE, dos programas de mestrado e doutorado da PUCPR.

\section{DESENVOLVIMENTO}

As reuniões de pesquisa do Grupo PEFOP têm articulado continuamente um fórum de discussão sobre a temática da formação pedagógica dos professores universitários. Em geral, os projetos desenvolvidos pelo grupo acolhem a pesquisa-ação como caminho investigativo, afinal, o grupo tem a clareza de que a mudança paradigmática da prática docente só acontece com a participação, o envolvimento e comprometimento dos professores envolvidos.

O grupo PEFOP desenvolve projetos de intervenção na formação de professores universitários. Por meio de pesquisa de pesquisa-ação, o projeto agora relatado tinha como objeto a investigação das impressões dos professores que participaram do processo, em especial, na disciplina de "Paradigmas Educacionais na Prática Pedagógica", nos últimos cinco anos (2003-2008). Tomou-se por base

Rev. Diálogo Educ., Curitiba, v. 10, n. 29, p. 27-44, jan./abr. 2010 
a participação de mais ou menos 20 professores universitários por ano, perfazendo um universo de 98 professores da educação superior que atuam em universidades federais, estaduais, particulares e nas faculdades privadas. Os participantes da pesquisa advêm de variadas áreas de conhecimento, e neste universo representado no relato, foram envolvidos 39 participantes das ciências humanas, 21 participantes das ciências biológicas e da saúde, 21 participantes das ciências exatas e tecnológicas, 11 participantes das ciências jurídicas e sociais e 6 participantes das ciências agrárias. Os 98 professores envolvidos receberam um número código (P.1 a P.98) para salvaguardar o anonimato dos participantes.

A atuação no grupo de pesquisa e a vivência como docente na proposta da disciplina permite desenvolver ano a ano, por meio de seminários temáticos e produções individuais e coletivas dos professores mestrandos e doutorandos, um fórum de discussões, rico e significativo, para buscar possibilidades de alterar a prática pedagógica dos docentes. Este relato apresenta a análise do processo de formação pedagógica dos últimos cinco anos. A discussão dentro do grupo PEFOP e o retorno dos alunos em cada ano possibilitaram a construção de um protocolo de acompanhamento das etapas do processo de formação. Cabe ressaltar que o grupo tem a clareza que uma única disciplina e um processo desenvolvido por quatro meses pode não desencadear uma profunda transformação na docência dos professores envolvidos, mas a experiência vivenciada e os relatos dos participantes permitem afirmar que ninguém sai desde processo sem a provocação para se aventurar num processo de mudança pedagógica em sala de aula.

Neste projeto foi realizado um levantamento do material coletado dos participantes durante as intervenções no processo formativo, ou seja, o registro das contribuições dos professores universitários (em cinco anos contínuos). A cada ano letivo, no início do processo de investigação com a nova turma, a pesquisadora explica a proposta do grupo PEFOP e propõe a discussão do desenvolvimento da disciplina de "Paradigmas Educacionais na Prática Pedagógica".

O envolvimento para participar na pesquisa-ação é feito por meio do convite e se realiza desde o início da disciplina. Os professores são consultados e podem com liberdade não aceitar participar da pesquisa. Os professores, em geral, assinam a carta de consentimento para se envolver no processo investigativo, mas sabem que estão livres para opinar, que não precisam aceitar a mudança paradigmática na ação

Rev. Diálogo Educ., Curitiba, v. 10, n. 29, p. 27-44, jan./abr. 2010 
docente e que este fato não interfere na avaliação da disciplina. A professora/pesquisadora abre o processo esclarecendo esses critérios e assegura o anonimato dos participantes na investigação.

Alguns pesquisadores do grupo PEFOP acompanham o processo e a discussão com os mestrandos e doutorandos sobre as temáticas propostas. Cabe ressaltar que os professores universitários que se inscrevem na "Linha Teoria e Prática Pedagógica na Formação de Professores e procuram o PPGE da PUCPR, o fazem exatamente pela possibilidade de discutir a formação pedagógica, pois este é um ponto forte do Programa. Desde o início, a grande maioria dos investigados apontam a vontade e a intenção de mudança na ação docente. Mas registram desafios enfrentados ao longo do curso, apontados pelos docentes universitários como o acúmulo de carga horária do Mestrado ou do Doutorado com as aulas na Graduação, alguns continuam atendendo também as responsabilidades como profissional de sua área de conhecimento, um grande número relata a dificuldade para realizar as leituras e as atividades propostas, outros indicam o enfrentamento do contato inicial com leituras fora de sua área de atuação, ou seja, textos focalizados na educação, entre outros enfrentamentos.

Convivendo ao longo deste processo de pesquisa, pode-se assegurar que o compromisso da discussão com o grupo leva os participantes a dar conta das leituras e das produções individuais, pois o envolvimento com os pares mediado pela professora/pesquisadora gera um pacto de entre-ajuda, de maneira geral, altamente solidária e produtiva.

A experiência vivenciada como docente e como coordenadora do grupo de pesquisa permite afirmar que existe um processo de reflexão e de mudança da prática pedagógica como pode ser percebida na produção de conhecimento, por meio dos artigos publicados pelos alunos e pelos pesquisadores, em eventos e em periódicos, e nas 106 dissertações de Mestrado no PPGE, defendidas sob a orientação do grupo PEFOP. O impacto da relevância do projeto tem sido registrado ao longo da história do grupo e pode-se afirmar que houve sempre uma interessante reflexão sobre a prática pedagógica na docência universitária.

\section{MARCO TEÓRICO DA INVESTIGAÇÃO}

O grupo PEFOP "Paradigmas Educacionais e Formação de Professores" vem investigando essa temática ao longo dos quatorze

Rev. Diálogo Educ., Curitiba, v. 10, n. 29, p. 27-44, jan./abr. 2010 
anos de sua existência e focaliza a pesquisa sobre os paradigmas da Ciência, da Educação e sua influência na prática pedagógica.

O foco das investigações nos paradigmas exige o esclarecimento do termo, pois na última década essa denominação tem aparecido com ênfase e tem surgido na literatura, em geral, quase sempre atrelado à proposta de Thomas Kuhn, na obra intitulada "A estruturas das revoluções científicas", na qual afirma: "Considero 'paradigmas' as realizações científicas universalmente reconhecidas que, durante algum tempo, fornecem problemas e soluções modelares para uma comunidade de praticantes de uma ciência" (KUHN, 2001, p. 13). E acrescenta que paradigmas propiciam visão de "conjunto de crenças e valores subjacentes à prática científica". Ainda segundo o autor, quando os fenômenos não se encaixam dentro deste padrão ou modelo ocorrem as anomalias no paradigma, gerando crise na ciência, impulsionando os cientistas a buscarem novas descobertas que respondam as necessidades de cada momento histórico, assim começa a construção de um novo paradigma. Segundo Assmann (1998), não há paradigma permanente, pois eles são historicamente mutáveis, relativos e naturalmente seletivos. Assim, com a evolução da humanidade, modificam-se os valores, as crenças, os conceitos e as ideias acerca da realidade. Essas mudanças paradigmáticas estão diretamente relacionadas ao olhar e à vivência do observador. Os paradigmas não se anulam linearmente, mas se entrelaçam e invadem o pensamento da comunidade científica e tomam força por um determinado tempo histórico.

Todas as áreas do conhecimento e a Educação têm sido influenciadas pelos paradigmas da ciência por toda a história da humanidade. A investigação sobre Paradigmas da Ciência ajuda a entender a proposta para Educação e a prática pedagógica. Esta temática nos leva a refletir que nos três últimos séculos o pensamento newtonianocartesiano vem caracterizando a Ciência e, por consequência, a Educação.

A visão newtoniana-cartesiana determinou a reprodução e a fragmentação do conhecimento (CAPRA, 1996, 2002; SANTOS, 1987; MORAES, 2004). Este paradigma conservador está muito presente na docência de muitos professores universitários que caracterizou a prática pedagógica assentada em atividades que envolvem ações como o escute, leia, decore e repita (BEHRENS, 2005, 2006). Os processos de memorização e repetição tornaram-se o foco essencial na docência. A Educação se contamina com o paradigma conservador e leva os pressupostos para as abordagens denominadas tradicional, escolanovista e tecnicista, que caracterizaram por longo

Rev. Diálogo Educ., Curitiba, v. 10, n. 29, p. 27-44, jan./abr. 2010 
tempo histórico a formação dos professores e dos profissionais em geral. No entanto, a ação pedagógica nessas tendências conservadoras enfoca o ensinar mesmo que esse processo não garanta o aprender. Neste sentido, o paradigma newtoniano-cartesiano agregou à ação docente uma visão reducionista e linear de ensinar e de aprender (BEHRENS, 2000).

As decorebas e a reprodução do conhecimento acabam não gerando uma aprendizagem condizente com as exigências da sociedade, em especial, a partir do final do século XX. A ruptura do paradigma da ciência assentada no movimento da física quântica desencadeou um processo de desmoronamento dos princípios do paradigma newtonianocartesiano. A superação do paradigma conservador e a necessidade de transpor a fragmentação e a divisão do conhecimento passaram a exigir da sociedade novos pressupostos paradigmáticos.

A razão para o desafio de superar o conservadorismo da prática docente prende-se a fatos maiores do que o contexto da sala de aula, da formação do professor e das próprias universidades. $\mathrm{Na}$ realidade, o paradigma que caracteriza a ação docente está atrelado ao movimento da própria ciência. Os docentes têm relutado em processar mudanças na prática pedagógica em função da forte influência do pensamento newtoniano-cartesiano que acompanhou a ciência desde o século XVIII. Assim, alerta-se que a mudança da ação docente está conectada ao entendimento dos paradigmas da ciência que vêm caracterizando ao longo dos séculos todos os segmentos da sociedade.

A partir das últimas décadas do século $\mathrm{XX}$, o movimento de mudança paradigmática numa visão complexa vem ganhando força por parte dos cientistas e também dos profissionais da Educação e de alguns professores universitários. O foco mais significativo na mudança paradigmática foi desencadeado pelo movimento da física quântica que aponta para uma dimensão complexa do universo e defende a visão da totalidade (MORIN, 2000). Essa influência paradigmática atinge a Educação e propõe a transformação da prática pedagógica, mas esta mudança depende da visão de mundo de cada professor. Com esse desafio posto, o docente precisa reavaliar sua prática pedagógica e, assim, buscar a superação da fragmentação com a tentativa de reintegração das partes.

O início do século XXI carrega a missão de desenvolver em plenitude um novo paradigma na ciência e na educação, denominado como emergente on da complexidade (CAPRA, 2002; MORIN, 2000; SANTOS, 1987). Essa constatação afeta também a prática pedagógica

Rev. Diálogo Educ., Curitiba, v. 10, n. 29, p. 27-44, jan./abr. 2010 
que passa a ter como eixo central os princípios da complexidade que exige a visão do todo, da conexão, do inter-relacionamento, de rede e de teia, entre outros. O advento da sociedade do conhecimento e as facilidades conquistadas pela rede informatizada levam a buscar metodologias que venham atender a um paradigma da complexidade e que gere a necessidade de produção do conhecimento, que implica em superar a reprodução, para problematizar, discutir, projetar, eleger informações relevantes, criar, entre outras ações pedagógicas.

Esses referenciais teóricos acompanham o grupo PEFOP e os caminhos investigativos se ampliam e geram necessidade de envolver outros docentes nessa caminhada de reformulação paradigmática na docência universitária. Esse propósito justifica a continuidade do grupo e envolve, ao longo dos anos, docentes universitários que acrescentam suas experiências e convicções para mobilização na busca de uma docência relevante, de melhor qualidade e que faça diferença na formação dos alunos da graduação.

\section{ENCAMINHAMENTO DA PESQUISA}

Neste artigo, optou-se por descrever uma das ações desenvolvidas pelo Grupo PEFOP, ou seja, a proposição da vivência na disciplina "Paradigmas Educacionais na Prática Pedagógica", mediada pela docente e coordenadora do grupo, num processo que agrega os professores universitários e tem sido um fórum permanente de discussão dos pesquisadores e dos alunos/participantes.

Numa primeira fase do caminho investigativo, os pesquisadores discutem também a proposição da disciplina, para tanto, começam discutindo e avaliando o contrato didático elaborado pela professora com: ementa, problematização, objetivos, contextualização, programação temática, metodologia e procedimentos, recursos, indicação de leituras e avaliação. Assim, os temas que compõem a ementa são projetados na proposta da disciplina e amplamente discutidos com o grupo PEFOP. O contrato didático permite a visão do todo e possibilita que os alunos/participantes possam opinar com uma ideia geral do que vai ser vivenciado no processo.

Numa segunda fase da pesquisa, os participantes tomam por base uma proposta de ementa que pode ser reformulada de acordo com as ideias dos mestrandos e doutorandos. $\mathrm{O}$ acolhimento das sugestões

Rev. Diálogo Educ., Curitiba, v. 10, n. 29, p. 27-44, jan./abr. 2010 
dos docentes que participam e participaram do processo gera a cada ano a construção da proposta refletida na ementa da disciplina, que, em geral, tem apresentado temas como: Paradigmas educacionais: conservadores e inovadores. O paradigma newtoniano-cartesiano e as abordagens conservadoras que visam à reprodução do conhecimento: tradicional, escolanovista e tecnicista. A superação do paradigma newtonianocartesiano e a ruptura do paradigma cartesiano e a busca do paradigma da complexidade na ação docente. A proposição de paradigma emergente ou da complexidade como elo de interconexão entre: abordagem progressista, visão holística e ensino com pesquisa. O desafio da construção de uma prática pedagógica num paradigma emergente ou da complexidade. Proposição de metodologia de projetos num paradigma da complexidade com uma proposta de aprendizagem colaborativa instrumentalizada pela tecnologia interativa. A organização do trabalho docente, o planejamento por meio dos programas de disciplinas e dos contratos didáticos e a avaliação contínua por portfólios.

Numa terceira fase, focaliza-se a problematização que foi composta e discutida com o grupo e com os alunos no início de cada processo. Assim, observa-se que ao longo dos cinco anos de pesquisa-ação, a problematização, tem se apresentado em torno da mesma temática, ou seja, o desafio de construir uma docência relevante, pois a maioria dos professores universitários ainda tem proposto uma prática pedagógica assentada em num paradigma conservador baseada no pensamento newtoniano-cartesiano, assim, oferecem aos alunos um ensino fragmentado que leva a copiar, decorar e repetir, ou seja, a reproduzir conhecimento. A necessidade de superação da abordagem conservadora na docência, em geral, leva a pesquisar o seguinte problema: A vivência no processo de formação continuada subsidiado pelos referenciais que caracterizam os paradigmas conservadores e inovadores na ciência, na educação e na prática pedagógica dos professores universitários ajudam a refletir e compor uma ação docente que atenda ao paradigma da complexidade e que leve a uma metodologia que busque a produção do conhecimento na Educação Superior?

A problemática é complexa e gera uma quarta fase, a composição dos objetivos relevantes que propiciem caminhos para responder a problematização. A apreciação dos objetivos pelos participantes, ao longo do processo, realça a importância de conectá-los com o problema, numa real vivência deste processo como alunos e como docentes em suas disciplinas na graduação. Detecta-se, em geral, que os professores propõe os objetivos sem entender esta conexão. Assim, focaliza-se como

Rev. Diálogo Educ., Curitiba, v. 10, n. 29, p. 27-44, jan./abr. 2010 
objetivo geral: analisar reflexivamente os paradigmas educacionais conservadores e inovadores e a sua influência na ciência, na educação e na prática pedagógica. E, como objetivos específicos: investigar os referenciais que caracterizam os paradigmas conservadores e inovadores na prática pedagógica; justificar a validade de optar por paradigmas inovadores no contexto educacional; discutir criticamente o papel do professor e sua metodologia na atuação docente inovadora; levantar, analisar e propor questões relevantes à opção paradigmática do profissional da educação; refletir sobre o professor como profissional e os novos caminhos na formação continuada dos docentes universitários; construir propostas metodológicas para uma prática docente num paradigma da complexidade; produzir conhecimento sobre paradigmas inovadores na prática pedagógica dos professores universitários.

A presença da contextualização no contrato didático ajuda a refletir durante a quinta fase do processo investigativo. Discute-se a relevância da proposta/disciplina e neste momento auxilia os alunos a entender a importância do processo da formação continuada no stricto sensu para formação pedagógica. Esta discussão sempre localizou os participantes e gerou o entendimento (nos cinco grupos investigados) de um compromisso com os pares na busca de uma docência universitária inovadora.

A discussão do esboço do marco teórico também é objeto de discussão na sexta fase da pesquisa. A partir da proposição da contextualização permite dar uma visão geral das temáticas que precisam ser desenvolvidas na disciplina. Assim, os participantes tomam conhecimento desde o inicio dos referenciais teóricos que compõem o processo formativo. Em síntese, durante os cinco anos, em geral, o marco teórico focaliza:

a) A influência dos paradigmas na ciência, na educação e na docência no ensino superior: abordagens conservadoras e a reprodução do conhecimento: Tradicional, Escolanovista, Tecnicista;

b) Os paradigmas contemporâneos e a ação docente. O paradigma emergente ou da complexidade: aliança entre as abordagens inovadoras e a produção do conhecimento: Progressista, Holístico e Ensino com Pesquisa;

c) Prática Pedagógica no ensino superior: O professor em relação a si mesmo e o seu papel docente. O professor em relação ao aluno. O professor em relação sociedade e universidade;

Rev. Diálogo Educ., Curitiba, v. 10, n. 29, p. 27-44, jan./abr. 2010 
d) Prática Pedagógica na Educação Superior: O professor em relação à metodologia. A superação da reprodução e a busca da produção do conhecimento;

e) Os processos pedagógicos e o professor como profissional reflexivo. Habilidades didáticas para aula expositiva;

f) Organização do trabalho docente num paradigma da complexidade. Programas de aprendizagem ou de disciplinas. Metodologia de Projetos. Contratos didáticos. Avaliação por portfólios.

A metodologia e procedimentos também foram propostos para discussão na sétima fase da investigação junto com os alunos participantes. A metodologia contempla a análise e discussão crítica dos paradigmas pedagógicos brasileiros conservadores e a sua influência no processo educacional e na docência focalizada na reprodução do conhecimento. Esta fase divide-se em três blocos, no primeiro, é proposta a leitura individual dos textos e o levantamento dos pressupostos teóricos e práticos do paradigma conservador em cada abordagem pedagógica: Tradicional, Escolanovista, Tecnicista. Assim, são organizados os encontros que permitem a ampliação em discussão das leituras realizadas visando à construção de quadro próprio à luz dos pressupostos teóricos dos autores propostos.

No segundo bloco desta fase é proposta a construção de referenciais que caracterizam os paradigmas pedagógicos contemporâneos refletindo sobre as abordagens inovadoras que compõem o Paradigma da Complexidade na busca da produção do conhecimento. Assim, focalizase a elaboração dos principais referenciais teóricos sobre os paradigmas educacionais inovadores: Progressista, Holística, Ensino com Pesquisa. Ainda neste bloco, os participantes produzem individualmente quadro sinóptico sobre os referenciais que sustentam os paradigmas educacionais propostos e discutem e elaboram coletivamente as principais características de cada abordagem inovadora. Os alunos participaram ao longo de todo o processo das discussões e apresentam as contribuições individuais e coletivas referentes aos temas propostos.

No terceiro bloco da proposta metodológica, os mestrandos e doutorandos exploram e produzem subsídios sobre paradigmas pedagógicos inovadores; discutem e relatam suas vivências a luz dos referenciais dos paradigmas conservadores e inovadores que

Rev. Diálogo Educ., Curitiba, v. 10, n. 29, p. 27-44, jan./abr. 2010 
caracterizam a vida de cada profissional e buscaram sua relação com a educação; produzem pequenos textos individuais e coletivos sobre os paradigmas conservadores e inovadores; ampliam o debate de temas relevantes apresentados por educadores inovadores referentes à influência dos paradigmas nos diversos segmentos da sociedade; como fechamento do processo metodológico, os alunos produzem um texto individual que subsidia a produção coletiva do artigo. Cabe ressaltar que esta elaboração foi sendo preparada ao longo da disciplina. Assim, o texto individual foi tomado como parâmetro de discussão entre pares (dois ou três alunos) para elaborar o artigo coletivo sobre a influência dos paradigmas na prática pedagógica dos professores universitários.

Durante a vivência neste processo de pesquisa foram utilizados múltiplos recursos, incluindo os mais tradicionais como o quadro de giz, livros e textos, mas na maioria das vezes foram utilizadas as novas possibilidades como datashow, acesso aos ambientes virtuais, consulta à rede informatizada e a obras disponibilizadas na internet, entre outros. A programação de utilização dos recursos inovadores pelo docente também é pensada para provocar os professores para utilizar esses recursos em suas aulas. A experiência vivenciada dos alunos usufruindo desses recursos pode provocar a reflexão da real pertinência no uso das mídias para o ensino e a aprendizagem (KENSKI, 2007; MORAN, 2006, 2007).

Para o processo avaliativo contínuo foram propostos procedimentos para compor o portfólio que foi desenvolvido de maneira processual pelos mestrandos e doutorandos. Entre os critérios avaliativos destacam-se: presença, pontualidade e participação nos encontros; investigação na rede de informação e na literatura sobre a temática proposta; leituras críticas realizadas com anotações e comentários; produção de síntese individual e coletiva em quadros sinópticos dos referenciais dos paradigmas conservadores e inovadores; participação efetiva nas discussões sobre temas propostos; produção e discussão de textos sobre os temas propostos; leitura, crítica, análise e posicionamento dos textos indicados; produção individual e coletiva de artigo final relacionado à temática sobre "Paradigmas Educacionais na Prática Pedagógica".

O caminho trilhado na pesquisa permite perceber que a ação docente precisa apresentar novos processos pedagógicos que contemplem problematizações que levem à reflexão, ao trabalho individual e coletivo, à negociação, ao espírito de entre-ajuda, à criticidade, ao envolvimento, à criatividade e, principalmente, à

Rev. Diálogo Educ., Curitiba, v. 10, n. 29, p. 27-44, jan./abr. 2010 
transformação da realidade. Para tanto, a proposição metodológica precisou envolver e atingir os quatro pilares: aprender a conhecer, aprender a pensar, aprender a conviver juntos e aprender a ser (DELORS, 1998). Este compartilhamento exige uma mudança profunda na maneira de conceber a docência e a metodologia do trabalho docente, ou seja, foram discutidos outros caminhos para ensinar e para aprender.

A concepção desta formação pedagógica focalizou como pressuposto essencial considerar em todos os momentos a riqueza da prática vivenciada de cada um dos participantes e os conhecimentos cotidianos dos professores. Com essa visão, é possível perceber que os saberes docentes são construídos ao longo da história de cada professor (TARDIF, 2002).

Os mestrandos e doutorandos envolvidos na pesquisa tiveram a possibilidade de refletir sobre a necessária reconstrução paradigmática da docência criando condições para que esses profissionais encontrem espaços para analisar sua ação docente, seus saberes e criarem caminhos compartilhados na construção de uma prática pedagógica competente e transformadora. O caminho trilhado individual e coletivamente instigou os participantes a investigar, pesquisar, revisitar, revisar, acrescentar, substituir e produzir conhecimentos para buscar uma prática pedagógica consubstanciada num paradigma da complexidade.

\section{CONSIDERAÇÕES FINAIS}

O desafio investigativo posto, elegeu uma das intervenções do grupo PEFOP, ou seja, a vivência dos professores universitários na disciplina de "Paradigmas Educacionais na Prática Pedagógica". O processo possibilitou uma reflexão crítica e reflexiva sobre os paradigmas da ciência e sua influência no processo educativo. Buscou-se investigar com os docentes envolvidos no estudo, a influência os paradigmas conservadores e inovadores e suas possíveis implicações na sala de aula. Provocou a discussão sobre a necessidade de transpor modelos conservadores e buscar a opção crítica de paradigmas inovadores, para tanto, investigou-se os pressupostos registrados ao longo da história da Educação, de cada abordagem pedagógica.

A grande maioria dos professores envolvidos aponta nos relatos sobre o processo investigativo que as dificuldades que enfrentam na docência estão muito atreladas à falta de formação pedagógica. $\mathrm{O}$ problema reside na possibilidade de que os professores que lecionam única e exclusivamente com o conhecimento do conteúdo possam

Rev. Diálogo Educ., Curitiba, v. 10, n. 29, p. 27-44, jan./abr. 2010 
enfrentar sérios desafios na ação docente improvisada, como relatam os próprios participantes. Dos relatos coletados, destaca-se:

\begin{abstract}
Comecei a dar aula na universidade e levei uns cinco anos no ensaio e erro para tentar propor uma metodologia para atuar na sala de aula. Ou seja, percebi que a aula teórica mantém os alunos em silêncio, mas comecei a ficar insatisfeito com o desfecho do processo, parece que os alunos não aprendiam e olhe que dou aula teórica todo tempo. Saia da sala de aula cansada e não conseguia perceber o mesmo envolvimento dos alunos. Eles ficavam pacificamente esperando e copiando o conteúdo do quadro de giz, como se isto garantisse a aprendizagem (p. 35).
\end{abstract}

O depoimento do professor envolvido na pesquisa reflete a problemática que acompanha grande parte dos professores que atuam na universidade, pois se sentem insatisfeitos com o que está acontecendo, mas não sabem como reconstruir sua prática pedagógica. Este fato, muitas vezes, move os docentes da Educação Superior a buscar uma modalidade de formação pedagógica. Essa formação pode ser frequentada em vários níveis, seja nas licenciaturas, nas especializações lato sensu designadas como Didática, na Metodologia do Ensino Superior, ou como no caso da PUCPR, denominada como "Formação Pedagógica do Professor Universitário". Porém, dos cursos stricto sensu em Educação, poucos são os que propõem linhas de pesquisa com foco na formação pedagógica dos professores.

A grande maioria dos professores envolvidos nesta pesquisa apresenta contribuições que podem mostrar a relevância da formação pedagógica, neste caso, em especial, no nível do stricto sensu. Assim, destacam-se depoimentos de docentes envolvidos no processo vivenciado:

Mas as instituições de ensino superior não deveriam esperar uma atitude individual do professor para buscar esta qualificação e oferecer propostas de processos de formação inicial e continuada que subsidiassem a reconstrução da prática pedagógica (p. 22).

Procurei o mestrado para ajudar a reconstruir minha docência, pois vinha enfrentando problemas com os alunos. Na vivência com os colegas, percebi que tratava os alunos com rispidez achando que este procedimento trazia seriedade para minha atuação como professor. Aprendi com os colegas que na mediação docente com os alunos precisa existir um pacto de comprometimento para buscar

Rev. Diálogo Educ., Curitiba, v. 10, n. 29, p. 27-44, jan./abr. 2010 
a aprendizagem e não é com ameaças que vai se atingir qualidade. Foi o que aconteceu comigo na vivência da disciplina de Paradigmas, esta experiência e discussão com o grupo me fez ver que serprofessor é algo muito maior que passar conhecimentos para os alunos. Sou hoje outro professor e me sinto mais valorizado, feliz na docência e com a sensação que posso fazer mais para a formação dos meus alunos como pessoas e como profissionais (p. 34).

A disciplina de Paradigmas possibilitou a experiência de viver uma proposta teórica com a vivência na prática de um novo paradigma na docência. A chance de conviver com outros professores e discutir com eles os procedimentos relevantes na docência me encantou e me deu mais segurança para mudar. A convivência na proposta e a proposição do contrato didático garantem que as discussões não passem de conversas, porque ao final de cada encontro, avaliávamos a possibilidade de migrar estes procedimentos, para nossa prática como professores universitários e as colocações ficavam justificadas teoricamente (p. 3).

Vim buscar uma formação pedagógica e encontrei respostas cientificas para justificar as minhas atitudes e a dos profissionais da minha área de conhecimento e fiquei motivado a propor uma docência com paradigma inovador para fazer diferença na minha própria vida acadêmica e, na vida e na formação dos meus alunos (p. 17).

Os relatos são significativos, pois a docência na educação superior tem sido questionada com ênfase nos últimos anos e são múltiplos os interferentes que caracterizam a prática pedagógica na universidade. De maneira geral, os docentes que atuam na universidade são escolhidos por sua projeção e competência enquanto profissional de uma determinada área de conhecimento. A pesquisa permitiu perceber que os docentes que buscaram o PPGE, embora possam ter domínio dos conteúdos e apresentem prática relevante para sua área profissional, em sua maioria, ou seja, aproximadamente, $72 \%$ do universo investigado, não tinham frequentado nenhuma formação pedagógica, em modalidade formal desde o início de suas carreiras como docente. Caberia perguntar se outras profissões aceitam que uma pessoa sem formação e experiência exerça um trabalho na comunidade? Na docência universitária é permitido e justifica-se que todos os profissionais foram alunos, portanto podem exercer a função de professor.

Rev. Diálogo Educ., Curitiba, v. 10, n. 29, p. 27-44, jan./abr. 2010 
A vivência na pesquisa permite alertar os professores que o conhecimento sobre sua área de atuação é imprescindível para lecionar na universidade, mas a busca da formação pedagógica pode interferir diretamente na metodologia que pode levar ao sucesso como docente, em especial, para que o professor não continue improvisando ao longo de sua carreira docente.

O panorama de mudança e inovação nas universidades tem ficado por conta da colocação de data-show em todas as salas de aula, sem a preocupação de oferecer aos docentes processos continuados de formação pedagógica para propor uma metodologia inovadora que envolva a utilização criteriosa deste recurso. Não se nega a grande valia do investimento nos recursos tecnológicos, mas sua utilização, por si só, não garante a alteração e qualidade da prática pedagógica numa visão complexa.

Outro fator marcante apresentado nos relatos foi que, em geral, as universidades oferecem no início do ano letivo uma semana pedagógica recheada de palestras com profissionais exponenciais. Essas propostas não tendem a gerar mudança efetiva na sala de aula, pois os profissionais convidados falam de uma teoria desarticulada da prática docente, e, em geral, esta proposta é esquecida pelos docentes que continuam perpetuando a prática pedagógica de seus antigos professores. A experiência vivenciada no grupo PEFOP com professores universitários permite afirmar que esses encontros servem como provocação, mas que os professores precisam de uma formação pedagógica continuada que se renove ao longo do processo para transformar a docência. Neste caminho formativo, as universidades precisam criar fóruns (reuniões) permanentes de formação pedagógica para os professores, em especial, para possibilitar espaço de discussão e orientação para os docentes que já se alertaram da necessidade de propor uma prática pedagógica inovadora que provoque a produção do conhecimento e que atenda a um paradigma da complexidade.

\section{REFERÊNCIAS}

ASSMANN, H. Metáforas novas para reencontrar a educação. São Paulo: UNIMEP, 1998.

BEHRENS, M. A. A formação pedagógica e os desafios do mundo moderno. In: MASETTO, M. (Org.). Docência na universidade. São Paulo: Papirus, 2000. p. 57-68.

. O paradigma emergente e a prática pedagógica. Petrópolis: Vozes, 2005.

Paradigma da complexidade: metodologia de projetos, contratos didáticos e portfólios. Petrópolis: Vozes, 2006.

Rev. Diálogo Educ., Curitiba, v. 10, n. 29, p. 27-44, jan./abr. 2010 
BEHRENS, M. A.; OLIARI, A. L. T. A evolução dos paradigmas na educação: do pensamento científico tradicional à complexidade. Revista Diálogo Educacional, Curitiba, v. 7, n. 22, p. 53-66.

CAPRA, F. A teia da vida: uma nova compreensão científica dos sistemas vivos. São Paulo: Cultrix, 1996.

As conexões ocultas: ciência para uma vida sustentável. São Paulo: Cultrix, 2002.

DELORS, J. Educação: um tesouro a descobrir. Relatório para Unesco da Comissão Internacional sobre Educação para o século XXI. São Paulo: Cortez, 1998.

KENSKI, V. M. Educação e tecnologia: o novo ritmo da informação. Campinas: Papirus, 2007.

KUHN, T. A estrutura das revoluções científicas. 16. ed. São Paulo: Perspectiva, 2001.

MORAES, M. C. Pensamento eco-sistêmico: educação, aprendizagem e cidadania no século XXI. Petrópolis: Vozes, 2004.

MORAN, J. M. Contribuições para uma pedagogia da educação online. In: SILVA, M. (Org.). Educação online. São Paulo: Loyola, 2006. p. 41-53.

A educação que desejamos: novos desafios e como chegar lá. Campinas: Papirus, 2007.

MORIN, E. Os sete saberes necessários à educação do futuro. São Paulo: Cortez; Brasília: Unesco, 2000.

SANTOS, B. S. Um discurso sobre as ciências. Porto: Afrontamentos, 1987.

TARDIF, M. Saberes docentes e formação profissional. Petrópolis: Vozes, 2002.

ZABALA, A. Enfoque globalizador e pensamento complexo: uma proposta para o currículo escolar. Porto Alegre: Artmed, 2002.

Recebido: 04/09/2009

Received: 09/04/2009

Aprovado: 30/10/2009

Approved: 10/30/2009

Rev. Diálogo Educ., Curitiba, v. 10, n. 29, p. 27-44, jan./abr. 2010 